\title{
Fatal Paradoxical Coronary Embolism
}

\author{
Maj PA Haynes \\ $M B, C h B, M R C P(U K)$, RAMC
}

Senior House Office

Department of Orthopaedics and Surgery, Duchess of Kent's Military Hospital, Catterick Garrison, North Yorkshire

SUMMARY: A case of a 53 year old man with fatal paradoxical coronary emboli is presented and the literatuox reviewed.

\section{Introduction}

Paradoxical embolism, the passage of embolic material from the venous to the systemic circulation through an intracardiac defect, most commonly presents as a cerebral event such as a stroke or transient ischaemic episode, or less frequently as a peripheral arterial occlusion. A case is presented of a patient who suffered a fatal myocardial infarction due to occlusion of both coronary arteries from a paradoxical embolism.

\section{Case report}

A 53 year old man was admitted with sudden onset of severe breathlessness. Twenty four hours before he had noticed some pain and swelling in his left leg. A few hours before his admission he suffered two episodes of breathlessness on exertion which improved over several minutes with rest. At no time did he complain of chest pain. Although a heavy smoker he had no previous history of ischaemic heart disease or respiratory problems. Mild hypertension had been noted about 2 years before. $\mathrm{He}$ took no regular medication.

On examination he was tachypnoeic. The breath sounds were vesicular. He had a tachycardia of 120 beats per minute and was hypotensive with a systolic blood pressure of $80 \mathrm{mmHg}$. The neck veins were engorged, a right ventricular heave and a gallop rhythm were noted. His left calf was swollen.

A chest $\mathrm{x}$-ray was unremarkable and the ECG showed ST elevation in leads V2 to V6. Arterial blood gas analysis showed a pH of 7.11, a PCO2 of 5.04 a PO2 of 7.27 and an oxygen saturation of $74.5 \%$. A clinical diagnosis of anterolateral myocardial infarction and pulmonary embolism was made.

The patient was given oxygen and thrombolytic therapy was commenced with streptokinase. Unfortunately within minutes of starting therapy he suffered a fatal cardiac arrest.

Post mortem revealed widespread thrombo-embolic occlusion in the pulmonary arteries. A left deep vein thrombosis was noted. The left anterior descending and the right coronary artery were both occluded by recent thromboembolic material. There was a still patent foramen ovale.
No evidence of mural thrombus was found and the heart valves all appeared normal. The left ventricte showed hypertrophy without fibrosis and the aordi showed only moderate atheroma.

\section{Discussion}

Paradoxical embolism and coronary artery embolisim are both rare events. Johnson's review of 82 cases of paradoxical embolism found that the coronary arterises were affected in only $7(1)$. In no cases were both coronay arteries affected. Another review of all causes of coronaly embolism found that in only 4 out of 54 cases were $\Phi$ th coronary arteries affected (2).

The case presented here of a fatal myocardial infargtion due to occlusion of both coronary arteries by parado embolism is, therefore, extremely rare.

According to Johnson(1), the diagnosis of paradofical embolism can not be considered verified unless at mortem the embolic material is caught, "red han straddling the patent foramen ovale, otherwise the diagnosis remains only presumptive. Establishing品 presumptive diagnosis depends on the presence of $\underset{\overrightarrow{\mathrm{Pe}}}{\overrightarrow{\mathrm{O}}}$ following:

1. A suitable venous source such as a DVT of the lower limbs or pelvic veins. Pulmonary embolism can be taking as a surrogate for such a venous source.

2. An intra-cardiac communication which is sufficien $\overline{\text { i }}$ large enough to convey the embolism. In a sme proportion of cases an atrial or ventricular septal defectus the culprit but for the most part a patent foramen ovaleăs implicated.

After birth the foramen ovale closes as a result of increase in left atrial pressure. Effective anatomiç closure usually follows (3) but a patent foramen ovide may remain in up to $35 \%$ of individuals. In $10 \bar{Q} 0$ consecutive autopsies studied by Thompson and Evans $(\Phi)$, $6 \%$ had a "pencilpatent" foramen ovale (0.6-1.0 diameter), whilst in a further $29 \%$ "probe patency" (0 $0.5 \mathrm{~cm}$ ) was present.

3. At some stage the normal pressure relationship that exists between right and left atria has to be reversed 0 permit a right to left shunt and thereby the passage off embolic material. In the majority of reported cases $(\mathcal{Q})$, 
pulmonary embolism is the antecedent event which leads to pulmonary hypertension and ensuing acute right ventricular impairment. Right atrial pressure increases and eventually exceeds that in the left atria.

However, other circumstances can lead to a reversed pressure gradient between right and left atria. The use of techniques such as cine angiography and more recently contrast echocardiography have shown that right to left shunting can occur during both the strain and release phases of the valsalva manoeuvre (6). Indeed in some reported cases of paradoxical embolism sudden onset of stroke or arterial occlusion of a limb has immediately followed coughing or straining at stool (7)(8).

Conventional treatment consists of surgical interruption of the inferior vena cava plus standard anticoagulation therapy. More recently(9), transcatheter closure of patent foramen ovale has been undertaken in 36 patients who had suffered a stroke or TIA and had a known right to left shunt and presumed paradoxical emboli. At a mean follow up of 8.4 months no further strokes occurred and little morbidity was reported.

A recent report (10) has suggested that the use of nitric oxide, a potent pulmonary vasodilator, may reverse the right to left pulmonary gradient created by a pulmonary embolism, thereby promoting closure of a patent foramen ovale. The authors suggest that it may be useful pending a decision to do a surgical or trans-catheter closure of a patent foramen ovale in patients with massive pulmonary embolism.

Since Conheim(11) reported the first case of paradoxical embolism over 100 hundred years ago, very few cases have been diagnosed ante mortem. Making such a diagnosis requires a high index of suspicion. In this case it was not considered but would have had no impact on the outcome as those suffering coronary embolism from any source usually succumb very quickly (2). The combination of pulmonary embolism along with evidence of systemic arterial embolism with no obvious systemic source, such as atrial fibrillation, mitral valve disease or left ventricular mural thrombus, should alert the clinician to the possibility of paradoxical embolism. The advent of contrast echocardiography, especially with provocative valsalva manoeuvres and more recently with transoesophageal echocardiography has provided $\frac{\mathrm{P}}{\mathrm{a}}$ reliable and non-invasive method of identifying a pate foramen ovale (8) and offer the prospect of a more raps and accurate ante-mortem diagnosis of paradoxica] embolism.

\section{Acknowledgement}

I would like to thank Lt Col J Dickinson for h permission to report on one of his patients.

\section{REFERENCES}

1. Johnson B I. Paradoxical Embolism. J Clin Path $\overrightarrow{\text { बa l }}$ 1951; 4: 316.

2. Shrader E L, Bawell M B, Moragues V. Corona年y embolism. Circulation 1956; 14: 1159-1163.

3. NELSON. Fetal and neonatal circulation. In: Vaugha $\overrightarrow{\mathrm{m}}$ V C, Behrman R E, eds. Textbook of Pediatrics, 134 Edn. Philadelphia: Saunders, 1987.

4. Thompson T, Evans W. Paradoxical Embolisi Quart J Med. 1930; 23: 135.

5. Corrin B. Paradoxical Embolism. Br Heart J 196 26: 549 .

6. Dubourg O, Bourdarias J P, Farcot J C. Contrast echocardiographic visualization of cough-induced right to left shunt through a patent foramen ovate. $J$ Am Coll Cardiol. 1984; 4: 587-594.

7. Loscalzo J. Paradoxical embolism: Clingc| presentation, diagnostic strategies, and therap options. Am Heart J. 1986; 112(1): 141-145.

8. Gautier J C, Durr A, Koussa S, lascaulo Grosgogeat Y. Paradoxical Cerebral Embolism \$ith a Patent Foramen Ovale. Cerebrovasc Dis $199 \mathrm{E}$ 撃: 193-202.

9. Bridges N D, Hellenbrand W, latson L, Filiano Newburger J W, Lock J E. Transcatheter closure of patent foramen ovale after presumed paradoxic embolism. Circulation 1992; 86(6): 1902-8.

10. Estagnasie P, Le Bourdelles G, Mier L, Coste DREYFuss D. Use of inhaled Nitric Oxide to rever蛋 flow through a patent foramen ovale durimg pulmonary embolism. Ann Intern Med. 1994; 12용 757-759.

11. CoNHEIM J. Allgem Path. 1877; i: 134. 